\title{
Una mirada a la cátedra de estudios afrocolombianos a partir de las reflexiones de los líderes de la Red Elegguá en la ciudad de Bogotá
}

\author{
An approach to the Afro-Colombian Studies from the reflections \\ of the leaders of Eleggua network in Bogota, Colombia
}

Ana Cristina Sotelo Manrique

Socióloga

Ex integrante del Semillero de Estereotipos y Ausencias Negras (SEAN)

de la facultad de Sociología de la Universidad Santo Tomás

anacrisoma@hotmail.com

Artículo de investigación

Fecha de recepción: 1 de noviembre de 2013 • Fecha de aprobación: 6 de diciembre de 2013

\section{RESUMEN}

A partir del análisis etnometodológico sobre las identidades configuradas por maestros e investigadores de la Cátedra de Estudios Afrocolombianos en la ciudad de Bogotá pertenecientes a la red Elegguá, se aborda una reflexión que se desprende de la crítica de esta red al proceso que bajo un supuesto multiculturalismo alberga un racismo sistemático naturalizado y transversal al orden social colombiano; así mismo se argumenta que uno de los factores que ha legitimado dicho proceso está ligado al Sistema Educativo Nacional encargado de su reproducción. Es decir, se sitúa el debate en la exigencia de cuestionar la educación tradicional del país anclada a la historia oficial y concepto de mestizaje, elementos que conforman los intereses monoculturales del proyecto de Estado Nación colombiano y que han impedido la implementación real de los reconocimientos étnicos de la constitución vigente. En este sentido la historicidad en esta investigación permitió mirar críticamente el lugar en el que permanecen los grupos subalternos, por lo que el abordaje teórico presenta una discusión frente a los límites culturales objetivos 
del esencialismo y constructivismo como posturas que no están lejos de las construcciones hegemónicas del Estado Nación.

Palabras clave: multiculturalismo, Raza, Mestizaje, Estado Nación, Etnicidad e identidades.

\begin{abstract}
From the etnometodological analysis which was done about entities created for the masters, investigators, leaders of the class from afrocolombian studies which belong to Elegguá network from Bogotá city, take up a reflection which comes from the criticism of this network to the process which under the figure of multiculturalism has a systematic racism naturalized and transversal to Colombian social order; likewise is argued that one of the factors which has legalized such process is joined to the national educational system charged of its reproduction. That is, the debate is located in the demand to question the traditional education of the country which has been fortified since the concept of mestizaje articulated to the monoculture interested of the project of Colombian Nation State which has impeded the real implementation of the ethnical recognitions of the in force constitution. In this way the historicity in this investigation permitted look at critically the place where in which stay the subaltern groups because the theorical approach present a discussion about cultural objective borders of the essentialism and constructivism as position which are not far from hegemonic constructions of the Nation State.
\end{abstract}

Keywords: Multiculturalism, racism, mestizaje, Nation State, ethnicity and entities.

\title{
INTRODUCCIÓN
}

En Colombia los grupos subalternos ${ }^{1}$ permanecen invisibilizados dados los preceptos del proyecto de Estado Nación, dichos preceptos se identifican con mayor vigor

1 Es una noción acuñada por Gramsci, que hace referencia a las definiciones históricas, culturales, sociales, etc. que una comunidad hace por oposición a la "cultura oficial" o hegemónica. 
en la constitución de 1886 donde se proclamaba una sociedad con "un sólo idioma, una sola raza y una sola religión”. Esta descripción será incompleta sí no se referencia que tales normas ayudaron a conformar el tejido de la monocultura hoy imperante en Colombia que se caracteriza por ser: católica, machista, mestiza e hispana; al respecto conviene señalar que de dichas características fue el mestizaje el que permitió consolidar de manera más contundente las bases preservadoras de la estructura piramidal heredada de la ciudad colonial que lega un orden social con base en la clasificación racial ${ }^{2}$ de la población, además dicha noción por un lado "encubría las diferencias socio-étnicas y por el otro salvaguardaba la discriminación hacia indígenas y negros" (Friedemann y Arocha, 1995, pp. 64-68). Lo que es peor aún, el mestizaje creó el imaginario de una sociedad ajena a la historia negra e indígena que es indiscutiblemente transversal a la genealogía y cultura de la misma y en consecuencia se desconoce el tejido historiográfico de la verdadera sociedad colombiana.

Ahora bien, se distingue que el Estado actual goza de una constitución que se declara multicultural y a través del artículo 7 proclama y acepta las diversidades étnicas, así como hace un reconocimiento de los diferentes grupos étnicos. $Y$ en la legislación en los decretos 804 de 1995 y en el 1122 de 1998 proclama unos reconocimientos educativos para la preservación étnica o con enfoque diferencial e incluyente, respectivamente; hay unas bases para afirmar que estos reconocimientos de manera fática se han quedado en supuestos dado el incumplimiento y la marginación política, económica, social y cultural del afrocolombiano e indígena. Dicha realidad además de atenuar el avance de los reconocimientos de la Constitución del 91, evidencia al tomar y delimitar en este caso específico los reconocimientos educativos étnicos, que la ley desconoce los marcos culturales heredados de una estructura social piramidal cuyo proyecto monocultural persiste en la actualidad a través de la educación colombiana que se resiste a la inclusión de las diferencias y se relaciona

2 El rastreo histórico del concepto de raza se remonta a las clasificaciones de los grupos humanas desde el s. XVI hasta la aparición de este concepto en el s. XVIII que respondió en su momento a las necesidades de unos centros de poder político-económicos en el afán de justificar el esclavismo para mantener su crecimiento económico. Hoy en día el avance de la ciencia a través del estudio del ADN mitocondrial evidencia que la especie no tiene divisiones naturales sino variaciones fenotípicas por lo que no existen razas. sin embargo en la escuela colombiana se insiste en el concepto de raza y poco se habla de la etnicidad y de las diferencias culturales existentes en el país. 
con el nacionalismo e historia oficial, como elementos que se articulan a la noción de mestizaje y raza.

Para ilustrar mejor las bases que sustentan tales afirmaciones hay que reseñar el proceso que dio origen a la Etnoeducación y a la Cátedra de estudios Afrocolombianos en el país, con lo cual ha de considerarse el decreto 804 de 1995, por medio del cual se reglamenta la atención educativa para grupos étnicos, ya que, establece que para la preservación cultural de estos pueblos es necesaria una educación pluriétnica, multilingüe e intercultural, razón por la cual la etnoeducación es un proyecto territorializado y endógeno que se desarrolla con un enfoque particular de acuerdo a las diferencias de cada grupo. Hasta aquí la ley habla de todos los grupos étnicos, no obstante, las comunidades negras presentan una variación que hace que la etnoeducación no sólo se enfoque al grupo étnico en específico, sino al resto de la sociedad colombiana y es a través de la Cátedra de Estudios Afrocolombianos (CEA).

Ahora bien, el antecedente de la cátedra de estudios afrocolombianos, de ahora en adelante CEA, se remonta al ańo de 1977 con el primer congreso de la cultura negra de las Américas celebrado en Cali, de acuerdo con Castillo Guzmán \& Caicedo Ortiz (2014). Esta organización, paulatinamente logró a través del Centro de Investigación de la Cultura Negra en el año de 1984, el V seminario de formación y capacitación docente en la ciudad de Mompox. Esto y los encuentros realizados por el Instituto Frantz Fanon, en 1986 en el Cauca, reconstruyen la memoria de todo un proceso que llegó al ańo de 1989 con el primer Encuentro Nacional de educación afrocolombiana en el cual se establecen las bases, lineamientos y objetivos de la misma. (p. 40).

La CEA para su reconocimiento legal pasa por un periodo donde se presentan asimetrías étnicas, dado que la constitución de 1991 mostró, como lo afirmaban Friedemann y Arocha, un "potencial sesgo ${ }^{3}$ del proceso que, resaltando la diferencia

3 El sesgo por lo indígena limitó la participación de las comunidades y activistas negros en la Asamblea Nacional Constituyente. Pero, y de acuerdo con Andrés Pulido (2010) hay que reconocer que la organización indígena caucana (CRIC) había alcanzado un gran nivel organizativo y también estaba nutrida de aportes academicistas 
cultural de las identidades indígenas, corría el riesgo de ocultar la etnicidad afrocolombiana" (Pulido, 2010, p. 260). Esta invisibilidad dio origen a una lucha de intelectuales y miembros del movimiento social afrocolombiano (Juan de Dios Mosquera, Otilia Dueñas, Mercedes Moya, etc.) que presionaron a los representantes de la Asamblea Nacional Constituyente por el reconocimiento de la etnicidad negra, con lo cual lograron que de manera transicional en el artículo $55^{4}$ se reconocieran las prácticas étnico-territoriales que finalmente dieron origen a la ley 70 aprobada hasta el año de 1993. Con esta ley en el año de 1998 se logra el decreto 1122 que deviene del movimiento social afrocolombiano ${ }^{5}$ cuyo mayor exponente fue el maestro Manuel Zapata Olivella, quién además fue el primero en proclamar la necesidad de que el Sistema Educativo Nacional incluyera los aportes de la diáspora africana al proyecto de Estado Nación.

De ahí que la CEA en el artículo 9, declare la obligatoriedad de la misma en la educación básica, media y superior, tanto pública como privada; puesto que nació como una herramienta que le permitiría a la sociedad integrar la realidad étnica con la academia, en otras palabras y en tiempo presente pretende incluir los aportes, historia y conocimientos de la cultura afrocolombiana negra, raizal y palanquera a la educación nacional creando espacios de reflexión crítica en cuanto a la invisibilidad de estas dimensiones subalternas en el país. Conviene, sin embargo, distinguir que a pesar de lo que significa la CEA, esta ha sido restringida y mal comprendida porque la institucionalidad colombiana ha establecido de manera inconsciente como lo afirma Garcés (2009) la historicidad de la dominación ${ }^{6}$ que a través de la

que permitieron elevar los valores de las culturas indígenas en el proceso de la nueva constitución aunque también marginar a la gente negra de los reconocimientos étnicos que se proclamaban para la nueva constitución.

4 El artículo aparece antes de la clausura de la Asamblea Nacional Constituyente, donde los representantes indígenas Rojas Birry y Lorenzo Muelas; y el sociólogo Fals Borda fueron los que más insistieron y se negaron a firmar la carta sin que apareciera este artículo.

5 Este movimiento a pesar de no ser reconocido, presenta una larga gesta de más de cuatro décadas en las que la propuesta de CEA nace como "Derecho, proyecto político y modelo de educación afrocolombiana" (Castillo Guzmán \& Caicedo Ortiz, 2014, p. 35)

6 La historia hegemónica incorporada en la escuela colombiana se ha enfocado en exaltar elementos ficticios a favor del nacionalismo, en tal sentido los hechos históricos narrados carecen de crítica e investigación con el fin de promover el sentimiento patriótico. Por ejemplo, no se menciona que Simón Bolívar, bajo la supuesta búsqueda de emancipar la "patria" de la corana española lo que quería en realidad era un beneficio propio ya que 
monocultura hegemónica no permite integrar de manera real las diferencias culturales al mantenerlas bajo categorías raciales, desde ese marco de referencia y de acuerdo con Yeison Meneses (2013) se han creado prejuicios y ficciones sobre la cátedra: La cátedra es de lo negro para lo negro, coordinada por el docente negro, dada sí hay estudiantes negros, sí no hay negros en las instituciones educativas para qué; debería existir una cátedra de "blanquitudes" para no generar discriminación (p. 13).

Dichas ficciones y prejuicios evidencian una institucionalidad que ha naturalizado la ignorancia, estereotipia e invisibilidad y por ende como lo expresa Elizabeth Castillo Guzmán (2014) hacen que la normatividad quede sometida a la voluntad de rectores, mandatarios locales y docentes; además la autora señala que en esto el Ministerio tiene una gran responsabilidad, pues hasta la fecha no ha sancionado a ninguna institución por no cumplir con el decreto 1122, mientras que en otros temas como el de las competencias ciudadanas, sí exige presión efectiva sobre directivos y docentes para llevar a cada aula las determinaciones oficiales, por lo que en materia educativa en Colombia es más grave obtener bajos puntajes en las pruebas PISA, que presenciar actos de racismo ${ }^{7}$ escolar cotidianamente a manos de niños, niñas, adolescentes y jóvenes (p. 2).

al ser criollo no tenía poder por lo que apenas la corona lo deja ejercer autoridad el proceso de libertad queda olvidado. También hay que mencionar que en dicho proceso a finales de 1813 para atraer a los esclavos y libertos, les ofreció la libertad absoluta si se sumaban al ejército de la independencia y hace la promesa una segunda vez cuando en un momento de crisis por falta de recursos pide ayuda en Haití al presidente Alejandro Petion, quien le facilita personal y pertrecho, a cambio le pide a Simón Bolívar, abolir la esclavitud de su pueblo si lograba la independencia, el "libertador" se comprometió con Petion, pero no cumplió su promesa. Su traición se hizo visible en el congreso de Cúcuta donde Antonio Narińo, vicepresidente interino de la república y representante del Presidente, hace conocer su propuesta de Manumisión de los esclavos. Puede asegurarse que no hizo mayor esfuerzo para que el congreso aboliera la esclavitud, cambió la libertad absoluta prometida por la "LIBERTAD DE VIENTRE”, lo cual quiere decir que los hijos de esclava que naciesen a partir de 1821 alcanzarían la libertad sólo después de cumplir 18 años y después de pagar los gastos de su manutención al esclavista. Riascos (2001) Vásquez (1994) \& Hernández \& Orobio (1998).

7 La investigación realizada por el centro de estudios Sociales de la Universidad Nacional de Colombia titulado: Mi gente en Bogotá, estudio socioeconómico y cultural de los afrodescendientes que residen en Bogotá (2002), luego de aplicar una encuesta en 19 localidades de la ciudad indicó que el 82\% de las prácticas de discriminación en la ciudad de Bogotá obedecen al color de piel. En el caso específico del contexto escolar, el análisis cualitativo del informe realizado en 16 colegios de la ciudad, reseńa diversos casos de discriminación racial detectados en diversas instituciones educativas, por ejemplo una docente niega a una niña con dones de poetiza sus habilidades porque considera que al ser negra sólo sirve para ser empleada de servicio doméstico por lo que en los recesos la obliga a barrer el colegio. Se recomienda consultar el informe ejecutivo: Investigando el racismo y la discriminación 
Además de dichas falencias se encuentra que pese a la legislación no hay programas específicos en pregrado y postgrado orientados a la formación en perspectiva afrocolombiana ${ }^{8}$ que contribuyan a mitigar e incluir la importancia de una educación que conozca y entienda las diferencias culturales, con lo cual se superarían las ficciones, ya que la cátedra como patrimonio de la sociedad colombiana no es "de lo negro para lo negro" sino que es un espacio que promueve el equilibrio de la historia; pluriversos; otros saberes y otorga herramientas para comprender qué somos como seres humanos lejos de las falacias recreadas por la versión oficial de la historia orientada a incentivar el nacionalismo.

Por esta razón y tomando a la ciudad de Bogotá como referencia, se indica que en el nivel de educación básica, los colegios distritales, 10 en total ${ }^{9}$ que han empezado a impartir la cátedra tienen pocos maestros formados en perspectiva afrocolombiana, el resto son, docentes ${ }^{10}$ que se ven obligados por unas cartillas a incluir el tema en sus respectivas materias; en los colegios privados ni siquiera existe dicha cátedra. En cuanto a la formación superior en los programas de ciencias sociales del sector privado de pregrado y postgrado no existen en las materias criterios específicos relacionados con el tema y en el sector de la educación pública hay un mayor reconocimiento

racial en la escuela (2009) coordinado por la Agencia Espańola de cooperación Internacional para el desarrollo (AECID) en asocio con la Secretaría de Educación Distrital (SED) que ha mostrado un interés junto con el gobierno Nacional para afrontar la problemática del racismo en la escuela.

8 La perspectiva afrocolombiana es el escenario de apropiación de la historia subalterna, de los procesos y desarrollos que estas comunidades han aportado al proyecto de Estado Nación. No obstante el mayor problema radica en el sistema educativo colombiano que poco ha creado espacios académicos y de formación profesional en este ámbito.

9 Información tomada del seminario: "Pedagogías para la inclusión y pensamiento decolonial afrocolombiano" realizado a partir del 20 de mayo del 2014 en la UNIMINUTO de Bogotá Colombia y verificada por la experta María Isabel Mena García.

10 El colectivo GEA - CES de estudios afrocolombianos de la Universidad Nacional de Colombia en el 2006 desarrolló un programa de formación permanente de docentes PFPD, del Distrito Capital de Bogotá, sobre la Cátedra de Estudios Afrocolombianos para los niveles de educación básica y media al constatar que las acciones pedagógicas diseńadas por estos docentes sin formación reforzaban en sus alumnos estereotipos muy arraigados. También advierten que son necesarias convocatorias que de manera explícita dibujen el tipo de expertos que deben contratarse para llenar vacíos que son, sin duda de carácter estructural (Arocha, Guevara, Londoño, Moreno, \& Rincón, 2007, p. 10) 
aunque limitado. Es decir, los programas ${ }^{11}$ para etnoeducación ${ }^{12}$ y para la cátedra son insuficientes por lo que las universidades que tienen programas de ciencias sociales desconocen la existencia de esta educación en temas étnicos, y por tanto, la obligatoriedad de los mismos se queda en el reconocimiento de papel.

Dentro de este contexto se evidencian las construcciones y apuestas de la red Elegguá, que desde el 2007 nace como una iniciativa de maestros e investigadores preocupados por la cátedra de estudios afrocolombianos y por los procesos afroetnoeducativos a nivel nacional; que han indicado que entre los muchos obstáculos para la realización de la cátedra, hay dos que sobresalen, el primero es que pese al marco legal no hay mecanismos que garanticen el cumplimiento de la ley en el país, ya que hacen falta procesos civilizatorios para legitimar su aceptación, en otras palabras, los procesos culturales de integración social promovidos desde la legislación son transversales al racismo colonial, es por ello que de manera sistemática, éste se ha perpetrado a través de los estereotipos y la invisibilidad, que en resumidas cuentas se sintetiza en la negación del otro a nivel institucional y sobre todo en el sistema educativo; y en segundo lugar no hay suficientes espacios de formación para docentes que deberían ejercer la cátedra y etnoeducación por lo que la manera de ejecutar la CEA no cuenta con profesionales capacitados y conocedores de los grupos subalternos.

11 En la Ciudad de Bogotá y pese al decreto 1122 de 1998 (CEA), no existen programas específicos pre graduales en estudios etnoeducativos y menos en formación de CEA. En Post grado hay maestrías en educación con énfasis en comunicación intercultural, etnoeducación y diversas culturas, caso de la Universidad Distrital Francisco José de Caldas. En la Universidad Pedagógica y Tecnológica de Colombia la maestría en educación tiene un grupo de investigación sobre: Etnicidad, colonialidad e interculturalidad; en la Universidad Externado llevan 2 semestres dictando una cátedra abierta de estudios afrodescendientes. Y según el listado de los programas en licenciaturas del ICFES en Bogotá, licenciatura en etnoeducación, la ofrece únicamente la Universidad Nacional Abierta y a Distancia.

12 De acuerdo con Daniel Garcés (2009) se afirma que existe un desafío social de atención formativa posgradual, frente a los 6121 plazos de etnoeducadores establecidos en el ańo 2005 y frente al potencial de los 12.932 aspirantes a etnoeducadores que presentaron la prueba ICFES para etnoeducadores afrocolombianos en junio 30 de 2006. En el 2008 los plazos de etnoeducadores de las entidades territoriales certificados de los departamentos de la cuenca del pacifico: Narińo, Cauca, Valle y Chocó, alcanzan la cifra de 4.268 plazas. En cuanto a la cátedra afrocolombiana que la regula el decreto 1122 de 1998, en el caso de Bogotá no hay programas que garanticen la formación de docentes para implementarla. Por lo que la gran mayoría de profesores encargados de la cátedra desconocen las dimensiones de esta apuesta educativa. 
De ahí que en el presente artículo a partir de la trayectoria de la red en investigación, formación de maestros y estudiantes desde una perspectiva afrocolombiana; y del reconocimiento previo de las identidades en torno a la CEA de los investigadores, maestros y líderes que la conforman, se establece una reflexión que invita a entender el por qué la complejidad étnica debe ser abordada desde el sistema educativo colombiano. Es decir, la necesidad de no sólo seguir insistiendo con el reconocimiento político y legislativo tan simbólico e inoperante, sino también de cuestionar un modelo educativo tradicional (desarticulado de su contexto social, de sus problemáticas, culturas e historias reales), recolonizador y monocultural que ha sido transversal a la invisibilidad y orden social colonial que deja el legado de razas.

\section{SOBRE LA NECESIDAD DE ESTUDIAR LAS IDENTIDADES SUBALTERNAS}

En Colombia las problemáticas étnicas siguen ocupando un lugar marginal en la realidad cultural, política y social, no obstante la insistencia en la invisibilidad y estereotipos en que permanecen estos grupos por parte de activistas, escritores, intelectuales y artistas, nacionales y extranjeros, han configurado perspectivas académicas, políticas y sociales que evidencian una largo recorrido en los estudios de las negritudes colombianas, con lo cual conviene distinguir que:

Actualmente, en términos teóricos la producción sobre poblaciones afrocolombianas se caracteriza por dos distinciones. Una generacional, esto es, los académicos que se formaron antes de los ochenta que continúan operando con categorías y enfoques convencionales, algunos de ellos positivistas. Y los académicos que entran en los noventa y que ahora tienden a manejar herramientas teóricas más contemporáneas que, a pesar de su diversidad, confluyen en las críticas al positivismo y a los modelos conceptuales funcionalistas, estructuralistas y ciertas versiones del afroamericanismo. La otra distinción refiere a la producción realizada desde la academia y la realizada desde las consultarías, ONGs, organizaciones sociales, e institutos gubernamentales. La primera producción se caracteriza por su sofisticación teórica y, en ocasiones, por su distanciamiento de las problemáticas más inmediatas de las poblaciones locales. En los segundos predomina un tono 
celebratorio del discurso multiculturalista acuñado en los noventa, así como una mayor preocupación por la coyuntura y problemas concretos que enfrenta la gente (Restrepo \& Rojas, 2008, p. 15).

De acuerdo con Eduardo Restrepo (2003) hay que tener en cuenta que la línea afroamericanista ha marcado la tendencia de la teoría social desde hace más de un siglo (p. 89) y pese a sus grandes aportes y diversas posturas presenta la debilidad de no cuestionar los desdibujamientos de los grupos subalternos tan naturalizados y preservados en el orden social jerárquico de la sociedad colombiana; en palabras de Fals Borda, deja de lado la obligación de abandonar el despotismo ilustrado con lo cual ha evitado construir una versión de la historia de abajo hacia arriba que ponga un equilibrio y genere desacuerdos frente a las falacias de la versión de la historia que ha creado el proyecto de Estado Nación.

Por lo anterior, en esta investigación y de acuerdo con tal compromiso, es necesario aclarar que aunque no se excluyeron valiosos aportes de la línea afroamericanista sí se distó de tal enfoque en el plano teórico, dado que por una parte este encuadre está lejos de cuestionar el papel de las ciencias sociales en el centro del quehacer hegemónico y por la otra le cuesta comprender a la etnicidad en el marco de relaciones de poder, razón por la cual se apuesta por el giro de los estudios culturales que no distan de enfoques etnometodológicos (reflexión por el orden social, el lugar del investigador y unidad de análisis en el proceso de indagación). En ese sentido fue menester comprender la etnicidad desde la subalternidad, es decir los líderes de la red Elegguá, hablan desde unas identidades que han configurado la resistencia ayudando a identificar como advierte Stuart Hall (1998) el campo ideológico en el cual se da la disputa entre representaciones sociales donde hay una hegemónica y otras subordinadas, dicho de otra manera no solamente fue darle voz al sujeto subalternizado, sino que fue dimensionar aquellos procesos que en el país han configurado la marginalidad de estos grupos lo que en síntesis es una reflexión por el poder que se enmarca en los esfuerzos por comprender el orden social colombiano.

Por ende las identidades de la red Elegguá configuradas a favor de la Cátedra de estudios Afrocolombianos en la ciudad de Bogotá, han evidenciado que está como: "derecho, proyecto político y necesidad de modelo de educación propio" es el 
intersticio de un multiculturalismo real, ya que plantea el reconocimiento de las diferencias desde el Sistema Educativo a nivel Nacional y no un reconocimiento que se queda sólo y para los poblados étnicos. Es decir el reconocimiento político de las diferencias o multiculturalismo hace referencia a todo un proceso que en Colombia, a excepción de la ley 89 de $1890^{13}$, aparece a partir de la constitución de 1991. Este es importante porque describe una primera declaración de las alteridades en el país, pero no deja de ser un proyecto político marginal dentro de un escenario colonial.

De acuerdo con la última afirmación, esto se debe a que el reconocimiento de la diferencia se ajustó a criterios endógenos dentro de la territorialidad de los grupos étnicos, (caso del decreto 804 de 1995) y en el caso de CEA, aunque presenta una excepción al ser propuesta para toda la sociedad, es invisible o no se ha implementado en la forma correspondiente. Es decir, no existen procesos con el resto de la sociedad de la importancia de las acciones afirmativas ${ }^{14}$, ni un reconocimiento exógeno (al resto de la sociedad no étnica) de estos grupos con su historia, lucha e identidad, dado que se mantienen coexistiendo en el marco de un poder hegemónico, con una monocultura, una historia oficialista y un nacionalismo que aísla y fragmenta el reconocimiento de las diferencias.

En otras palabras, el reconocimiento de los diferentes según Touraine (2000) es la encrucijada de caminos: entre una democracia cultural que reconoce el pluralismo cultural (y los derechos de las minorías) y un integrismo comunitario que identifica un poder con una sociedad y una cultura (p. 173). Cabe señalar que hay un

13 Durante un siglo y un lustro de vigencia de la constitución de 1886 por obvios preceptos no se reconocían a los grupos étnicos, a excepción de los indígenas con la ley 89 de 1890 que aprobaba la figura del cabildo aunque bajo categorías racistas y etnocidas. Esta ley sirvió un siglo después cuando el Consejo Regional Indígena del Cauca (CRIC) se apropió de esta herramienta legal dotándola de un nuevo significado para lograr la autonomía política y territorial de estos pueblos, con lo cual llegan a la Asamblea Nacional constituyente del 91 con una organización solida al respecto.

14 Sí bien todos los seres humanos somos iguales en cuanto a dignidad humana, hay unos procesos que nos diferencian: culturales, históricos, etc. En el caso de los grupos subalternos las condiciones de invisibilidad y los marcos de miseria en que permanecieron durante tanto tiempo, crean la deuda del Estado para ponerlos en condiciones de igualdad para que puedan acceder a los mismos derechos del resto de la sociedad, a eso se hace referencia cuando se habla de acción afirmativa; pero esto no equivale a que el Estado les otorgue mayores beneficios y recursos que al resto de población sino que se toman medidas que logren ponerlos en condiciones de equidad con respecto al resto de colombianos. 
relativismo cultural, puesto que "se ambiciona la separación de culturas definidas por su particularidad, y con ello la construcción de sociedades homogéneas" (Touraine, 2000, p. 176). Lo que en efecto hace que el multiculturalismo en este caso, defina a los grupos étnicos bajo categorías raciales y territoriales que los mantienen aislados de un reconocimiento por parte de toda la sociedad, lo mismo que juntos, pero no revueltos ${ }^{15}$. Este último parámetro establece una diferencia cultural muy importante, en este caso seria el énfasis en que las diversidades culturales pueden estar en un mismo espacio sin tener que integrarse. Lo cual emplaza a los indígenas y negros a la invisibilidad y por ende se coloca al mestizo en el mito de "raza" superior dentro de las demás y como grupo hegemónico dentro del proyecto de Estado Nación.

Por lo anterior es necesario estudiar las identidades subalternas porque de manera consciente o inconsciente se configura la representación y la resistencia de estos grupos, para este caso es evidenciar que no existe la ausencia afro y por ello los afrocolombianos no son los huérfanos de la historia ${ }^{16}$. Es decir, la importancia de elaborar una aproximación a la representación propia de los grupos subalternos, pero también leer las paradojas de una realidad social que por una parte ha legitimado el racismo, y que por omisión y herencia colonial le ha costado mirarse a sí misma y reconocerse como la sociedad culturalmente indígena, negra y campesina que es.

\section{El PELIGRO DE LAS LECTURAS HEGEMÓNICAS DE LAS IDENTIDADES}

Para comprender este apartado hay que tener en cuenta la lectura que se hace del concepto de identidades desde dos corrientes en las ciencias sociales: esencialismo y constructivismo. El primero hace referencia al reconocimiento de las alteridades

15 Según Grimson (2000) estas diferencias culturales en Argentina reposan en la creencia de que el argentino es por la mezcla de razas europeas, lo cual deja sin lugar al indígena y al negro en el relato oficial de Nación; en EEUU según DaMatta, referenciado por Grimson, se sintetiza en la frase “iguales pero separados” y en Brasil la norma es “diferentes pero juntos” en el caso de EE UU las diferencias están dadas en las relaciones sociales en el caso de Brasil las diferencias están dadas en la ausencia de estas relaciones (p. 49).

16 Hoffmann (2007) en sus reflexiones académicas señala la perspectiva de mostrar las construcciones históricas, políticas, sociales y culturales que desmienten el precepto euroccidental de señalar a la diáspora africana y a los afrodescendientes como los huerfanos de la historia. 
desde el plano político, hablando de quiénes son los sujetos y cómo deben ser para pertenecer a un grupo étnico, lo cual define lo étnico con base a patrones culturales objetivos, es decir, se da por asimilado que la cultura es un concepto objetivo y de allí subyacen términos como raza y territorio, que se articulan a posturas nacionalistas y monoculturales. Y el segundo:

Como casi postura de sentido común en los investigadores sociales contemporáneos, crea algunas ficciones reguladoras — como la de la contrastividadpara señalar ciertos efectos teóricos, políticos y etnográficos que resultan de basar los análisis en una "performatividad cliché». Lo que Brubaker y Cooper (2001) llaman «constructivismo cliché». Una especie de afirmación prescriptiva que nos lleva a repetir que las identidades son: construidas, contrastivas, situacionales, fragmentadas, fluidas, flexibles y disputadas (Briones, 2007, p. 58).

Si bien, hay que tener en cuenta que la estructura y la agencia son transversales a las ciencias sociales, la manera de abordarlas también hace parte de un marco conceptual ligado al proyecto de modernidad eurocentrista, (aunque hay que tener cuidado, ya que ambos enfoques no pertenecen a un corpus unificado y determinante, por lo cual, sólo se enfatiza en como abordan el concepto de identidad) en tal sentido vale decir que el constructivismo y esencialismo con respecto a las identidades no dejan de "inscribirse en el centro más que en los márgenes del que hacer hegemónico" (Briones, 2007). Sin embargo, el derecho a la identidad y la diferencia desde los trabajos de campo supera, discute y niega muchas pre-concepciones teóricas que aún son el punto de partida de investigaciones sociales, como por ejemplo, la poca claridad al diferenciar cultura e identidad, cultura compartida o heredada, etc.

Frente a esta problemática Frederick Barth (1976) construyó un punto de inflexión al analizar en los grupos étnicos y sus fronteras que partir de elementos culturales objetivos: (lingüísticos, territoriales, fenotípicos, etc.) reducen los campos de comprensión de lo qué es la etnicidad y la vinculan a comprensiones que se encuentran ancladas a los intereses de la cultura dominante, por ejemplo no se es afrocolombiano por nacer en un determinado territorio, o por tener unas características fenotípicas (color negro en la piel) ni hablar otra lengua; ya que hacer fijaciones de lo que es el 
otro desde la visión monocultural ha negado las identidades de aquellos que teniendo piel negra no se reconocen como afros ni como negros, sino, como campesinos, citadinos, mestizos etc.; o de aquellos de piel negra que han vivido, nacido y crecido en una ciudad y que son hijos de padres citadinos y por ende no se reconocen como afrocolombianos; pero también niega a aquellos que siendo de piel blanca e hijos de afrocolombianos, se definen y se reconocen como tal; sencillamente la piel, lengua y territorio deberían ser variables desligadas del pertenecer o no a un grupo étnico, ya que con ellas se anula el lugar de enunciación de la etnicidad y se hace una comprensión desde elementos racistas que tejen los mitos del Estado Nación. Por lo que:

La cultura no es sino una forma de describir la conducta humana, se podría concluir que existen grupos de individuos, es decir, unidades étnicas correspondientes a cada cultura: tanto las diferencias de las culturas como sus límites históricos han recibido atención suficiente. Por el contrario la constitución de los grupos étnicos y la naturaleza de los límites entre éstos no han sido investigadas en las formas correspondientes (Barth, 1976).

Por consiguiente este autor lejos de volver a las definiciones tradicionales de grupos étnicos como:

Comunidad que: 1. En gran medida se autoperpetúa biológicamente; 2 . Comparte valores culturales fundamentales realizados con unidad manifiesta en fonemas culturales; 3. Integra un campo de comunicación e interacción y 4. Cuenta con unos miembros que se identifican a sí mismos y son identificados por otros y que constituyen una categoría distinguible de otras categorías del mismos orden (Barth, 1976).

Advierte que dicho punto de partida que considera la cultura como algo objetivo, imposibilita entender el fenómeno de los grupos étnicos y su lugar en la sociedad mayoritaria de la cual se diferencian. Es decir la pregunta no es ¿Qué características hacen que alguien pertenezca a un grupo étnico? sino ¿Cómo se construye la etnicidad? ¿Cuál es su importancia? ¿Por qué alguien pertenece a un grupo étnico?, así se encuentra que la primera pregunta busca fijar límites culturales en cambio 
el segundo bloque obliga a pensar cómo y desde donde surge la diferencia, su importancia y un lugar de enunciación. En otras palabras los grupos étnicos no son islas y los reconocimientos políticos insisten en esto.

Por lo anterior, conviene distinguir que no se trata de seguir definiendo al grupo por sí mismo "sino el contenido cultural que encierra" (Barth, 1976) dado que la primera perspectiva abordada desde el esencialismo social pone acento a las definiciones étnicas "objetivas" que terminan siendo los límites fijados por la monocultura imperante, por esta razón el esencialismo como abordaje teórico no ha identificado a partir de la realidad subalterna existente cómo y bajo qué pretextos hay unos significantes hegemónicos que le ponen límites a la etnicidad con lo cual evade la urgencia de poner en tela de juicio los reconocimientos políticos constitucionales que reposan en las fronteras puestas por la hegemonía monocultural. En cambio la segunda perspectiva parte de identificar las relaciones, sentidos y lugares de enunciación que conforman el tejido de la subalternidad identificando el cómo se constituye y porqué es importante la diferencia.

En cuanto al constructivismo el problema fundamental es que alberga la expectativa de explicar lo que la gente hace o debiera hacer con base a quiénes son o a qué cultura pertenecen (Briones, 2007) lo cual, es muy determinista y está lejos del punto de vista del sentido que los sujetos dan a sus prácticas, además si por ejemplo, las identidades están en proceso de construcción o son abiertas, múltiples y contradictoras, entonces, "no pueden manifestarse como totalidad", es decir, la fragmentación atribuida por el constructivismo debería orientarse más a sostener que lo fragmentado, equivale más a las posiciones de los sujetos pero esto no implica que las prácticas sociales también lo estén, de acuerdo como lo afirma Hall, citado por Briones, atribuirle de forma preliminar al sujeto que sus prácticas son fragmentadas es además de arbitrario una negación de la materialidad, porque esta no se agota en la acción social, pero también decir que el campo de significados es meramente discursivo, está desvinculando el pensamiento como lo real. Por tanto, la posición constructivista en vez de hacer que el enfoque de las ciencias sociales se centre en comprender la identidad y la diferencia como efectos del poder, privilegia el orden del quehacer hegemónico puesto que tal como Briones señala, se parte de unos límites trazados por la performatividad que deberían ser más los límites del constructivismo como abordaje teórico. 


\section{REDEFINICIONES DE LAS IDENTIDADES}

Privilegiar el punto de vista del sujeto además de señalar una historia de abajo hacia arriba evita que la teoría social siga estando en la centralidad del quehacer hegemónico, por lo que, de acuerdo con Rodríguez referenciado por Restrepo "escuchar la voz del subalterno en tanto sujeto-agente de su propia historia implica una "lectura en reversa" de la historia libre de las distorsiones, borramientos y desdibujamientos insertados por el elitismo" (Restrepo, 2005, p. 177). Con esto y de acuerdo al punto de inflexión señalado por Barth, las identidades lograrían escapar y ser rastreadas desde su constitución y no desde los límites culturales objetivos.

Ahora bien, en segundo lugar el concepto de identidades está atravesado por las relaciones de poder, por lo que, es frecuente que muchos intenten hablar de una identidad nacional, pero el nacionalismo está lejos de leer las identidades de los diferentes grupos sociales como lo explica Alejandro Grimson, ya que, no se puede concebir o hablar de una cultura colombiana porque "esa pretensión de homogeneidad cultural constituye un elemento de legitimación del poder estatal y debe ser comprendida como acto político" (Grimson, 2000, p. 27).

En tercer lugar, se debe abordar las identidades étnicas mencionando el concepto de diferencia, ya que este término es la sutura entre el yo y el otro así lo sostiene Stuart Hall (2000) cuando afirman que las identidades se construyen a través de la diferencia, no al margen de ella. Esto implica la admisión radicalmente perturbadora de que el significado "positivo" de cualquier término — y con ello su «identidad»sólo puede construirse a través de la relación con el Otro, la relación con lo que él no es, con lo que justamente le falta, con lo que se ha denominado su afuera constitutivo (p. 18).

Sin embargo, la diferencia se remite al poder porque el yo y el otro se encuentran en un contexto específico, en unas circunstancias que devienen de procesos de larga duración que han dejado sus huellas, es decir, las lecturas que hace un otro del diferente son productos de marcos institucionales que conservan desde una mirada en apariencia moderna cimientos del orden social colonial. Entonces, no es gratuito que ser "negro" signifique para alguien que no sea negro un color de piel y 
un territorio y esto debe entenderse dentro de un marco de relaciones de poder, ya que está señalando quien define al subalterno, por ejemplo:

Los ingleses son racistas no porque odien los negros, sino porque no saben quiénes son sin los negros. Tienen que saber quiénes no son, para saber quiénes son. Y la lengua inglesa está absolutamente repleta de cosas que los ingleses no son. No son negros, no son indios o asiáticos, pero no son europeos tampoco, y así sucesivamente. En Piel negra, máscaras blancas de Fanon, hay un pasaje fantástico sobre el Otro cuando él habla de cómo la mirada del Otro lo fija en una identidad. Él sabe lo que es ser negro cuando la nińa blanca tira de la mano de su madre y dice: "mira mamá, un negro". Fanon dice "fui fijado en esa mirada”, que es la mirada fija de la Otredad. Y no hay identidad sin la relación dialógica con el Otro. El Otro no está afuera, sino también dentro del uno mismo, de la identidad. Así, la identidad es un proceso, la identidad se fisura. La identidad no es un punto fijo, sino ambivalente. La identidad es también la relación del Otro hacia el uno mismo (Hall, 2010, p. 344).

De acuerdo con este ejemplo, en el caso de Colombia el desconocimiento del otro parte de unas pautas de blanqueamiento social como herencia cultural de un orden social colonial, en donde se han naturalizado de manera inconsciente comportamientos de diferenciación de razas que son acordes a los intereses de la monocultura hegemónica, si bien, el racismo en Inglaterra es más dado a la violencia física en Colombia es más a la violencia simbólica y esta sutileza lo hace parecer inexistente haciéndolo más cruel y peligroso.

En cuarto lugar, es cierto que la piel, el territorio o la lengua no hacen a alguien afro o indígena, pero es pertinente hacer referencia a un lugar de enunciación, esto porque si bien toda la humanidad es una única especie, no toda la humanidad es culturalmente afro, es decir, se insiste en confundir en las teorías sociales lo cultural y lo biológico, en este caso, aunque, la especie comparte una ascendencia en común y no presenta divisiones naturales dentro de la misma (no existen razas), esto no implica que en términos socio-culturales sea de la misma manera ya que no toda la humanidad es afro o indígena o tiene un marco histórico y una memoria relacionada con la historia africana, la trata, el esclavismo, exterminio cultural, etnocidio etc., es decir: 
Quiero argumentar que la etnicidad es lo que requerimos para pensar la relación entre la identidad y la diferencia. ¿Qué quiero decir con esto? No hay manera, me parece a mí, en la cual las personas del mundo pueden actuar, hablar, crear, entrar desde los márgenes y hablar, o puedan comenzar a reflejar en su propia experiencia, a menos que vengan de algún lugar, de alguna historia, de heredar ciertas tradiciones culturales. Lo que hemos aprendido acerca de la teoría de enunciación es que no hay enunciación sin posicionalidad. Uno tiene que posicionarse en algún lugar en aras de decir cualquier cosa. Así, nosotros no podemos prescindir de ese sentido de nuestra propia posicionalidad que es connotado por el término de etnicidad (Hall, 2010, p. 345).

Con esto la posicionalidad señala un punto de referencia importante y es que es afro o negro ${ }^{17}$ aquel que reconoce y comparte elementos de una historia en común, dimensiones culturales en común, sentidos, significados y prácticas comunes; con lo cual la etnicidad señala una relación de un individuo con el pasado, un pasado que de acuerdo con Hall (2010) se sostiene a través de la memoria. Por tanto, hoy hablar de etnicidad emergente señala la necesidad de un lugar desde el cual hablar pero no únicamente de nuestra etnicidad de forma estrecha y esencialista. Eso es la nueva etnicidad. Es una nueva concepción de nuestras identidades porque no ha perdido el asidero del lugar y el suelo desde el que podemos hablar, pero ya no estamos contenidos dentro de ese lugar como una esencia. Da cuenta de una más amplia variedad de experiencias. Forma parte de la enorme relativización cultural que el globo entero alcanza históricamente — de modo horrible como ha sido en parte- en el siglo XX. Esas son las nuevas etnicidades, las voces nuevas. No están encerradas en el pasado ni son capaces de olvidarse del pasado. No son del todo lo mismo, ni enteramente diferentes. Identidad y diferencia. Es un arreglo nuevo entre la identidad y la diferencia (p. 347).

17 Los referentes afro (local, lugar de origen) y negro (Relación con la trata, esclavismo y diáspora africana) hacen parte de dos referentes identitarios complejos que por un lado otorgan un sentido de etnicidad, un lugar de enunciación y origen como puntos comunes de configuración de identidades étnicas, y por el otro hablan del ser arrancado de África y traído por la fuerza a América. 
Esto insiste en entender a los individuos desde marcos e historias devenidas de una memoria cultural, lo cual señala una recuperación cultural de ese vacio de conocimiento al hablar del otro. Esto es de vital importancia, puesto que en las teorías sociales decir que no se es afro por el color de la piel, territorio o lengua no está muy presente como sí los rasgos fenotípicos, lingüísticos y territoriales. Entonces al decir que no se es afro por el color de la piel o territorio es correcto, pero se necesita complementar la idea haciendo distinción de la ascendencia biológica humana y lo socio cultural, de lo contrario se estaría privilegiando de nuevo el quehacer hegemónico dado que en ese sentido cualquiera podría ser afro y no, aquí se señala que no, porque esto, es privilegiar el oportunismo de algunos actores sociales que se aprovechan de estos discursos para llegar a tener posición en espacios del gobierno, por lo que:
El momento esencializante es débil porque naturaliza y deshistoriza la diferencia, y confunde lo que es histórico y cultural con lo que es natural, biológico y genético. En el momento en el que el significante negro es separado de su entorno histórico, cultural y político y es introducido en una categoría racial biológicamente constituida, como reacción, le otorgamos valor al mismo cimiento del racismo que deseamos erradicar (Hall, 2010, p. 295).

Por tanto, un criterio para abordar el concepto de identidades fue entender y separar las diferencias de las necesidades intelectuales de un centro de poder políticoeconómico como lo es el Estado Nación colombiano y de uno socio-cultural subalterno y marginado. En último lugar, las identidades son constructos discursivos por lo que "debemos considerarlas producidas en ámbitos históricos e institucionales específicos en el interior de formaciones y prácticas discursivas específicas" (Hall, 2000 , p. 19). Lo cual implica que hay una construcción hablada que permite interpelar la propia subjetividad definiendo qué "soy" como individuo. Sin embargo, ese axioma revela poco "sobre la causa por la cual algunos individuos ocupan ciertas posiciones y no otras" (Hall, 2000). Por lo que, es más pertinente asumir la lógica del discurso de la identidad:

Un sujeto fijo; es decir, hemos asumido que hay algo que podemos llamar nuestra identidad lo cual, en un mundo rápidamente cambiante, tiene la gran 
ventaja de aún permanecer. Las identidades son una clase de garantía de que el mundo no se deshace tan velozmente como a veces parece. Son una especie de punto fijo del pensamiento y del ser, un fundamento de la acción, un punto aún existente en el mundo cambiante. Ésa es la clase de última garantía que la identidad parece proporcionarnos (Hall, 2010, p. 238).

En este sentido y de acuerdo con Hall, el sujeto que habla pertenece a una historicidad, a un pasado que aunque no se puede verificar, sí se puede entrar a comprender el cómo se configura este, el cómo un sujeto in terroga su propia historia y se dimensiona a partir de allí. Por tanto, las identidades nos remiten a las esferas de comprensión intersubjetiva, tal cual lo afirma Grimson (2000) comunicar es “poner en común”, es hacer común, público, algo. Para poner en común, un sentido compartido de ciertas cosas. Para entender un mensaje debo entender el código de mi interlocutor (p. 16). Es decir, los símbolos, universos y significantes que representan un punto de partida y la profundidad del ser deben ser puestos en el contexto del sujeto que cuenta la historia, razón por la cual para un investigador de las identidades afro es indispensable un proceso previo de caracterización de la otra versión de la historia, pero también debe tener en cuenta como lo afirma Restrepo (2005) que el conocimiento científico se produce para transformar y revertir un conjunto de relaciones de poder específicas en las cuales el "negro" ha sido subalternizado. Esta transformación se puede lograr cuestionando la centralidad de las ciencias sociales en el quehacer hegemónico para crear rupturas definitivas y sacar al subalterno de los estereotipos e invisibilidad.

\section{ENFOQUE ETNOMETODOLÓGICO: LA IMPORTANCIA DE DARLE VOZ AL SUBALTERNO}

Esta investigación fue exploratoria, cualitativa de corte descriptiva e interpretativa, en ese sentido la necesidad de usar un diseño cualitativo concierne a que no es un estudio de la realidad en sí, sino de la construcción de la realidad, (Rodríguez Gómez \& Otros, 1996) con esto se hace referencia a que la realidad está trazada y tejida a partir de múltiples procesos culturales, políticos, sociales y elementos históricos de larga duración que al remitirse al contexto de la unidad de análisis evidencian una 
serie de causas que los han puesto como grupos subalternos dentro de las jerarquías y orden social colombiano. Así pues es menester aclarar que la orientación fue holística y concretizadora diferente de particular y generalizadora (Del Val Cid \& Gutiérrez Brito, 2005).

Por lo anterior la primera razón que justifica este diseño cualitativo es una discusión frente al positivismo dado que este como paradigma y marco de referencia en la investigación social no es útil para resignificar los nuevos sentidos y construcciones del sujeto hacedor de la realidad, es decir comprender cualitativamente implica ir más allá de un ejercicio taxonómico, una escogencia de variables y unos resultados reduccionistas, ya que esto impide hacer reflexiones mucho más complejas sobre las múltiples interconexiones de procesos que permean la realidad del sujeto; lejos de abrir viejos debates entre los métodos cualitativos y cuantitativos simplemente hay que aclarar que la investigación cuantitativa es útil para otro tipo de estudios, en cambio el que nos atañe aquí y como segunda razón presenta tres categorías emergentes: Diferencia, pertenencia social y etnicidad, que se operacionalizan con mayor reflexión desde la investigación cualitativa porque esta permite indicar que dichos conceptos a pesar de ser abordados teóricamente aún presentan un vacio de significado que los han dejado en el centro de patrones culturales objetivos que poco cuestionan la realidad del orden jerárquico colombiano y poco se han mirado desde las ciencias sociales como efectos del poder.

La tercera razón es de orden axiológico y esto se relaciona con el giro epistemológico de la etnometodología que en primera medida hace frente a la neutralidad valorativa, es decir la pretensión de objetividad al estudiar un hecho social queda en el marco del deber ser (Coulon, 1993) porque en la realidad fática los sujetos investigadores pertenecen a la sociedad que indagan y por esta razón han adoptado posiciones ético-políticas que difícilmente logran desvincular del proceso investigativo. Esto no quiere decir que el investigador se ate a sus emociones sino que asume una posición y entiende que el sujeto investigado no es un ignorante de su realidad porque la crea, la construye y la dota de significados, es decir los sujetos no pueden ser vistos como seres incapaces de entender sus propios contextos. 
Por tanto partir de allí, permite que la postura investigativa deje de tratar los fenómenos sociales como cosas (discusión frente al positivismo de Durkheim), ya que la vida social es construida a partir de los individuos que no están coaccionados por fuerzas impersonales que los orientan; de esta manera, se resignifica el eje fundamental del estudio de la interacción humana desde el campo de la pragmática que permite ampliar el núcleo de conocimiento de la disciplina, porque hace repensar la concepción básica de la sociología y es que lo que diferencia al hombre de las sociedades animales es la cultura, pero ésta cultura o visión de mundo es de acuerdo con Darton (2009) el lugar de donde emanan los procesos cognoscentes de las interacciones humanas y a pesar de que el individuo es inconsciente de la cultura la construye, tiene la interpretación y las estrategias para hacerle frente a su mundo.

En síntesis el enfoque etnometodológico ayudó a entender desde el sujeto conocedor de la subalternidad la lucha de este en el orden social. Es decir complejiza la etnometodología de Garfinkel (2006) con los trabajos de Darton (2009) y pese a que la centralidad de estos son los enfoques fenomenológicos cognoscitivos, hay que señalar que estos no distan del enfoque escogido; al contrario tienen en común la importancia de orientar la investigación a la comprensión del contexto del sujeto y significado que este le atribuye. Dicho diálogo implicó más que entender las estrategias y métodos con los que el "sujeto conocedor de la subalternidad" hace frente a su mundo, entender desde este las claves y significados afros/negros de aquellos procesos que hacen frente al escenario social, político y cultural construido a partir de las herencias coloniales.

De acuerdo con lo anterior las identidades de los líderes de la cátedra de estudios afrocolombianos en la ciudad de Bogotá, hacen parte de un proceso de larga duración anclados a las luchas subalternas que pretenden visibilizar estas luchas y dar a conocer lo aportes de la etnicidad afrocolombiana, con lo cual para identificar la trayectoria social de los líderes de "la red Elegguá", se utilizó la documentación previa, observación no participante y finalmente la entrevista antropológica a profundidad, técnicas que permitieron evidenciar que pese a que los líderes cuentan con estudios de niveles de maestría o doctorados; la formación en perspectiva afrocolombiana ha sido un proceso alterno a través de las memorias del movimiento social afrocolombiano y 
educación popular ${ }^{18}$, enriquecido desde sus campos de estudio, ya que esta perspectiva es bastante invisible en los diversos niveles de educación porque sencillamente el sistema educativo colombiano "multicultural y pluricultural" oferta muy pocos programas relacionados específicamente con el tema.

\section{LAS VOCES de la RED Elegguá fRENTE A LA MONOCUlTURA Transmitida EN el Sistema Educativo Nacional}

Hay que tener en cuenta que la monocultura transmitida en el sistema educativo nacional es producto del proyecto de Estado Nación y de acuerdo con Anderson (1991) el Estado Nación y nacionalismo como puntos de partida, son artefactos culturales de una clase particular. Y a fin de entenderlos adecuadamente, necesitamos considerar con cuidado cómo han llegado a ser en la historia, en qué formas han cambiado sus significados a través del tiempo y por qué en la actualidad tienen una legitimidad nacional tan profunda (p. 21). En este sentido es de vital importancia señalar que la invisibilidad y los estereotipos en que permanecen los grupos étnicos, corresponden en gran parte a los artefactos culturales recreados desde el sistema de educación a través de versiones de la historia oficial que incentivan el nacionalismo.

Por lo anterior hay que hablar de un sistema educativo cuyo dispositivo de transmisión cultural más destacado ha sido el mito de "razas" (por ejemplo los textos escolares padecen un blanqueamiento social tanto en sus contenidos como en las ilustraciones); por lo que hay que señalar que este término inscribe y proyecta una serie de elementos históricos de dominación y sometimiento que nacen del proyecto de la colonia en donde los llamados mestizos no eligieron esta condición. Al contrario, fue impuesta con la historia oficial y con el proyecto de colonia cuyo orden se mantuvo intacto para el proyecto de Estado Nación, que fue posible según Margarita Chávez (2002)

18 La educación popular es una corriente político-educativa que surge en Latinoamérica. Aunque su origen se remonta a finales de los años 70 por las apuestas y pensamiento del pedagogo brasileńo Paublo Freire, sus antecedentes comenzaron con la teología de la liberación e ideales de la izquierda latinoamericana, ya que estas perspectivas fueron las que aportaron herramientas para intervenir en los sectores populares y generar cambios desde los contextos y no desde aulas de clase bancarias que desde abstracciones teóricas reducen la posibilidad de transformación social. 
por la estratificación social basada en el color que desempeñó un papel importante en las sociedades coloniales latinoamericanas.

En donde una vez apareció el mestizo como ser biológico y político-cultural, y el orden sociopolítico colonial se encontró plenamente establecido, indígenas y negros podían intentar convertirse o llegar a ser mestizos por medio del abandono de sus comunidades y la adopción de prácticas culturales y valores europeos, tales como la lengua española y el cristianismo, en un proceso que algunos autores han denominado blanqueamiento; durante el siglo dieciocho, el orden colonial clasificó a las personas mediante un intrincado sistema de graduación del color de la piel y de otros rasgos fenotípicos definidos en relación con los colonizadores europeos. En la así llamada sociedad de castas, el blanqueamiento y la limpieza de sangre asociada con las elites blancas — criollos americanos y españoles — eran claves en la posición social de los individuos, mientras que el oscurecimiento de la piel se relacionaba con la proximidad a los negros y a los indios y, por tanto, era signo de atraso, pobreza e ignorancia. Este orden jerárquico prevaleció hasta finales del siglo diecinueve, cuando entre las élites nacionales e imperiales se arraigaron concepciones específicamente raciales sobre las diferencias sociales y culturales (pp. 195-196).

Actualmente la concepción de "razas" sigue presente en el sistema educativo, en donde la persistencia que transmite del orden de la ciudad colonial se encuentra en lo que es hoy el orden de la sociedad colombiana, no en el sentido material (construcción física de ciudad) sino en el plano simbólico porque, de acuerdo con Ángel Rama (1998), este plano ayudó a implementar las categorías de raza: blancos y mestizos a la cabeza, indios condición baja y negros por fuera de la pirámide. Por tanto pese a que la sociedad colombiana tiene la característica de ser triétnica, la negación de este elemento se debe principalmente a la educación devenida de tal jerarquía que además ha naturalizado un racismo sistemático que tiene la peculiaridad de estar inscrito en la ambigüedad del mal orientado interculturalismo educativo ${ }^{19}$, en donde se presenta el

19 De acuerdo con Fidel Mosquera, Doctor en ciencias y educación de la Universidad de Navarra, la interculturalidad educativa nace en Europa como producto de las constantes inmigraciones que causaron que dentro de un salón de clase existieran grupos sociales con diferentes características, idiomas, culturas etc. Es decir, el encuentro de los nacionales con gentes de otros países hizo que este escenario fuera tenso para los docentes que tuvieron que implementar estrategias para enseńar los contenidos de clase. Sin embargo, la interculturalidad no nació 
legado colonial de clasificación racial en apariencia superado, pero preserva en esencia los cimientos de la pirámide colonial a través de la realidad jerárquica de clasificación social.

Por lo anterior al emplazar tal realidad al posicionamiento de estos líderes, en materia de la cátedra de estudios afrocolombianos ${ }^{20}$, hay que empezar por evidenciar que la importancia de la misma está ligada a visibilizar los aportes de la cultura afro en una ciudad y Estado que se ha encargado de invisibilizar esta alteridad. Es decir, hay una ausencia de lo afro en los planes de estudios del sistema de educación de la sociedad colombiana que niega ser triétnica, por lo que:

"No se conocen los aportes de la cultura afro a lo que ha sido la construcción del proyecto de Estado Nación, entonces, esa es la importancia que tiene la cátedra en el sistema educativo. Que nosotros prácticamente, sí tú miras los textos, muy mal se ha educado la gente en este país. Nosotros no existimos para la historia, ni nada de esas cuestiones, entonces hay unos aportes muy importantes de nuestras culturas y lo que fue el proyecto de nación desde todos los campos, desde la lingüística, desde la misma historia, etc" (Comunicación personal de Fidel Mosquera, 27 de Octubre, 2014).

Es decir existe la necesidad de justicia y reconocimiento social de la otra historia, la que está marginada de la realidad educativa y cultural colombiana. Por lo que se evidencia "la necesidad de empezar a construir nuevos textos, porque los textos que tenemos en nuestro sistema educativo hay que deconstruirlos, es decir, que nos acerquen a una realidad que nos permita estudiar todos estos temas que tienen que ver con las diferencias y diferentes culturas de los pueblos que forman parte de la

pensándose las diferencias étnicas dentro de un mismo marco nacional, ya que, es una problemática que difiere del contexto europeo. Por ende limitarse a la perspectiva intercultural educativa no dice nada de cómo deben ser reconocidas, abordadas las diferencias existentes en un mismo país, etc. Caso que es propio y nace en la etnoeducación.

20 La CEA presenta ocho dimensiones, entre ella los saberes ambientales que buscan enriquecer la escuela con otras cosmovisiones, con otras miradas, otras historias y formas de relacionamiento con el mundo, la naturaleza y los otros. No obstante no se profundiza en las otras dimensiones dados los límites del artículo. 
nación colombiana. Y eso es algo, que no siempre es fácil de trabajar" (comunicación personal de Fidel Mosquera, 27 de Octubre, 2014).

Ahora bien, esta necesidad no debe ser aislada de la lucha contra el racismo, y este último no debe ser reducido a las lógicas de superioridad que "x raza" afirma tener, frente a otra " $x$ " que asimila desde su entendimiento como "inferior"; porque sería arrancarlo de los referentes genealógicos de la realidad triétnica del país, pero además de los símbolos y sentidos de comprensión que la sociedad colombiana encierra dentro de su orden jerárquico, es decir, hay varias formas de negar al otro, pero la forma como el grupo social niega al otro responde a una comprensión muy simple: "Es negro por el color de la piel". Por ejemplo, aquella foto publicada en la revista Hola, que presenta en primer plano a cuatro mujeres de la alta sociedad caleña, específicamente la familia Zazur, y muy detrás muestra dos mujeres empleadas domésticas de piel negra posando con charolas de plata, sosteniendo café, ha pasado por varios análisis, en donde en reiteradas ocasiones diferentes estamentos de la sociedad y diversos analistas sociales se han escandalizado.

Sin embargo, dicho escándalo deja entrever el desconocimiento que esas personas tienen de los grupos étnicos y de sí mismos, dado que hacen énfasis, no tanto en la subordinación de las mujeres dada la posición ridícula, el vestuario que llevan, y la manera caprichosa en la que se ven obligadas a aparecer en la escena de la foto, sino en el color de la piel. Sí por ejemplo, y de manera satírica, se afirma, que sí la foto hubiese presentado a dos mujeres empleadas domésticas con otro tono de piel ningún analista, o estamento de la sociedad habría considerado la escena de esa fotografía. En resumidas cuentas el narcisismo (el ideal de blanqueamiento) de la sociedad colombiana ha sido llevado a todas las esferas (institucionales, científicas, académicas, etc.) donde se vuelve a reproducir desconocimiento del subalterno, dándole poca importancia a elementos que son más profundos e importantes.

Es decir, la negritud o lo afro se limita tanto a esta característica, que de manera escueta las esferas de comprensión humana, social, medios de comunicación, universidades, etc., están esquivando el comportamiento naturalizado de la realidad en la que viven; por tanto, y en definitiva las realidades étnicas no han sido profundizadas, por lo que, 
la formación de maestros críticos y no repetitivos aportaría a conocer al otro más allá de un color de piel.

Por lo anterior y parafraseando a María Isabel Mena, la cátedra se encuentra con dos situaciones básicamente: se encuentra con el racismo de Estado y el racismo de Estado cae sobre los maestros, cae sobre los textos escolares, se repliega y se recrudece, digamos, sobre los propios niños afros, negros. Y ésta cátedra entonces, tiene una situación de inexistencia, ella es invisible en el sistema educativo nacional lo cual hace que "el racismo institucional recaiga de manera más protuberante, sobre todos los niveles del sistema educativo dejando de lado una falta de comprensión de qué somos como seres humanos y como comunidades negras en un país como Colombia”.

Así pues se debe mencionar el desconocimiento que albergan las diferentes esferas sociales de la realidad racista naturalizada y presente cuya causa más relevante es un sistema educativo que promueve el proyecto nacionalista a través del mestizaje. Este elemento siendo abordado de manera crítica y reflexiva permitiría reconocer la existencia de unas comunidades puntuales que albergan un pasado que se relaciona con la trata y exterminio de culturas, un pasado que como diría Hall, no ha sido borrado con el transcurrir del tiempo. Este pasado debe ser reconocido por esa sociedad que ignora sus contextos, ya que, permitiría ampliar la educación a múltiples miradas y paradigmas. En este sentido, los líderes hacen énfasis en un desconocimiento del racismo, y sin este último "no habría necesidad de la cátedra de estudios afrocolombianos" (comunicado personal de María Stella Escobar Benítez, 28 de Octubre, 2014).

Por lo anterior, conviene distinguir que el espacio que se está reclamando para la CEA y etnoeducación en un contexto como el colombiano está asociado a un modelo educativo que necesita ser reestructurado dado que: "Es la reivindicación de los diferentes grupos étnicos y sus derechos. Aparte de los derechos humanos también está el derecho a la educación y tener una educación con un enfoque diferencial en derechos étnicos. Entonces yo creo que eso es pertinente, así como por ejemplo se nos ha impuesto una educación que no se corresponde con nuestra cultura, que es una educación que está ligada al proyecto de la colonia, entonces, eso por ejemplo, a 
mí me parece gravísimo, sobre todo lo que tiene que ver hoy en día con la formación de los niños y de los jóvenes aquí en este país" (Comunicación personal de María Isabel Mena García, 17 de Febrero, 2015).

Por lo anterior, la CEA es un escenario que permitiría transformar el modelo educativo tradicional y vincular a la academia y a las ciencias sociales más con el contexto y la realidad de los pueblos étnicos, campesinos, diferentes clases sociales, problemáticas ambientales, etc., en este sentido la Cátedra de Estudios Afrocolombianos se encuentra como el puente para pensar una educación más crítica, que integre, y que reduzca como modelo estereotipos étnicos, sociales, raciales y de saberes de otras culturas. En últimas una educación cuya mayor importancia en síntesis y palabras de María Isabel Mena García es:

Una oportunidad valiosísima de entenderse como comunidad, o ¿Qué es esto de tener por lo menos tres grupos étnicos en el interior de la sociedad colombiana?... La cátedra representa un patrimonio, un patrimonio social y la cátedra tiene un valor digamos, que la cátedra en esto fue mucho más revolucionaria que la misma etnoeducación, porque la cátedra, digo este conjunto de saberes aplicados a la escuela tienen que irse para todos los niveles... (...) Entonces la cátedra seria aquella oportunidad de la sociedad colombiana de mirarse a sí misma, de poner una especie de espejo, sí, para mermar un poco el narcicismo que el racismo implica.

Para terminar hay que aclarar que la CEA no es la solución al modelo de educación tradicional del país, pero sí representa un escenario que tiene en cuenta un modelo de educación más incluyente con los diferentes grupos sociales, con otras cosmovisiones y otros saberes que podrían aportar a un modelo educativo nacional autóctono; otro aporte importante es que la monocultura y los legados coloniales en los que un individuo denominado colombiano crece, han naturalizado un racismo, y este concepto no se debe reducir a comprensiones fenotípicas: el blanco vs negro o viceversa, sino a la invisibilidad, negación y desconocimiento del otro, también a los prejuicios que se han construido de ese otro. Estos son la base de que el sistema educativo necesite este modelo enriquecedor. 


\section{APORTES A LOS INVESTIGADORES E INVESTIGACIONES SOCIALES}

Haciendo un balance de los hallazgos más relevantes de las reflexiones de los líderes de la red Elegguá, hay que comenzar por señalar que frente a los límites culturales objetivos que otorga la constitución de 1991 a los grupos étnicos también hay un racismo sistemático transversal en la sociedad e instituciones, que a través de la educación logra mantener el orden jerárquico heredado de la colonia, así pues cabe preguntarse ¡cómo o desde dónde se debe plantear un multiculturalismo real? Es decir, la complejidad étnica debe ser asumida y entendida más allá de los reconocimientos políticos y legislativos; y aunque se propone y se apuesta por el sistema educativo como escenario para construir el puente que llegue a dicho fin, aún la tradición monocultural del proyecto de Estado Nación está en los cimientos del sistema educativo ¿cómo modificar esta realidad?

En segundo lugar, si bien en los reconocimientos "multiculturales" de la constitución de 1991 hubo en principio un sesgo por lo indígena, hoy en el plano educativo a pesar de que la CEA es una propuesta rica que está regulada y decretada para toda la sociedad presenta un sesgo por la afrocolombianidad, es decir se reconoce que hasta la fecha esta no se ha ejecutado dado el racismo de la institucionalidad colombiana, pero esta propuesta es inequitativa frente a las comunidades indígenas que deberían también tener un decreto educativo regulado diferente al 804 de 1995 que es de carácter endógeno. Con esto no se quiere decir que el reconocimiento legislativo y constitucional en el plano educativo presenten sesgos por lo afro en detrimento de lo indígena, porque esto sería bastante absurdo dadas las condiciones de marginalidad de estos temas en el sistema educativo nacional, por lo que expresado de otro modo, lo que se quiere decir es que lejos de pensar ingenuamente que el país es más indigenista que afrocolombianista o lo inverso, se debe dejar en claro que no hay tal perspectiva, con lo cual se pregunta ¿Cómo hacer que los debates de la inclusión de los aportes étnicos en la educación no caigan en los discursos que afirman el sesgo por lo indígena o lo afro?

En otras palabras los procesos de asimetrías étnicas han tenido varias tendencias pero en el plano educativo, de acuerdo con el panorama actual desvían la problemática a posturas que se quedan en debates académicos y no emplazan la problemática a la 
realidad inmediata, que desde el interés de esta reflexión se sintetiza en cómo incluir los aportes étnicos al sistema educativo, ya que es esté el encardo como lo afirma Gramsci de "reproducir la sociedad que tenemos", en este caso una sociedad que no ha dejado el narcisismo ciego (ideales de blancura) y que le ha costado reconocerse en el espejo como lo que es.

En tercer y último lugar no se puede negar la realidad del mestizaje, lejos de ser una categoría biológica es una realidad socio-histórica que debe comprenderse tanto para cuestionar el narcicismo de la sociedad colombina como para pensar en el reconocimiento de la diferencia real. Con esto se hace referencia a la necesidad de que las academias reconozcan aquellos elementos naturalizados a partir del orden social que han creado ciertas ficciones que llevan a desdibujar o a negar el racismo tan naturalizado en la sociedad colombiana, en este sentido es preguntar por ¿Cuál es el lugar de los grupos subalternos en la sociedad colombiana de hoy?

\section{REFERENCIAS}

Anderson, B. (1991). Comunidades imaginadas. Reflexiones sobre la difusión y origen del nacionalismo. Méjico: Fondo de Cultura Económica.

Arocha, J., \& Friedemann, N. (1995). “Colombia”. En: No longer Invisible. Afro - Latin Americans Today. London: Minority Rights.

Arocha, J., Guevarra, N., Londoño, S., Moreno, L., \& Rincón, L. (2007). Elegguá y respeto por los afrocolombianos: Una experiencia con docentes de Bogotá en torno a la cátedra de estudios afrocolombianos. Estudios sociales. pp 94-105.

Barth, F. (1976). Los grupos étnicos y sus fronteras. México: Fondo de cultura económica.

Briones, C. (2007). Teorías performativas de la identidad y performatividad de las teorías. Tabula Rasa (6), 55-83. 
Castillo Guzmán, E. (2014). La voz precursora de Manuel Zapata Olivella y la Cátedra de estudios afrocolombianos. Bogotá. Centro de memorias étnicas.

Castillo Guzmán, E., \& Caicedo Ortiz, J. A. (2014). Entre invisibilidad y reconocimiento Luchas afrocolombianas por la educación en el siglo XX. Educación y Cultura FECODE (103), 35-47.

Coulon, A. (1993). Etnometodología y educación. Barcelona, Buenos Aires, México: Paídos.

Chavez, M. (2002). Jerarquías de color y mestizaje en la amazonia occidental colombiana. Revista colombiana de antropología, 38, 189-216.

Darton, R. (2009). La gran Matanza de gatos y otros episodios en la cultura francesa. México: Fondo de cultura económica.

Del Val Cid, C., \& Gutiérrez Brito, J. (2005). Prácticas para la comprensión de la realidad social. Madrid: McGraw-Hill.

Garcés, D. (18 de Mayo de 2009). Desafíos y tensiones sobre la formación de etnoeducadores afrocolombianos. Buenaventura: Universidad del Pacifico.

Garfinkel, H. (2006). Estudios en etnometodología. Bogotá: Anthropos

Grimson, A. (2000). Interculturalidad y comunicación. Buenos Aires: Norma.

Hall, S. (1998). Significado, representación, ideología: Althusser y los debates posestructuralistas. En Curran, James, Morley, David, \& V. Walkerdine, Estudios culturales y comunicación. Buenos Aires: Paidos.

Hall, S. (2000). Introducción: ¿Quién necesita identidad?

Hall, S. (2010). Sin garantías: Trayectorias y problemáticas en estudios culturales. Popayán Colombia: Envión editores. 
Hernández, O., \& Orobio, A. (1998). Manual para Delegados de la Palabra en NoanamáChocó. Popayán: Universidad de Popayán.

Hoffmann, O. (11 de Agosto de 2007). Población de origen africano y afrodecendiente. Recuperado el 14 de Septiembre de 2011, de Las américas negras contemporáneas: http:// cemca_14articulo.UNAM

Meneses, Y. (2013). Representaciones sociales sobre etnoeducación y cátedra de estudios afrocolombianos en la formación del profesorado. Enunciación. pp. 5-19.

Pulido, A. (2010). Violencia y asimetrías étnicas. Multiculturalismo, debate antropológico y etnicidad de los afrocolombianos (1980 - 1990). (F. d. sociales, Ed.) Antipodas (11), 259-280.

Rama, A. (1998). La ciudad letrada. Montevideo: ARCA

Restrepo, E., \& Rojas, A. (2008). Afrodescendientes en Colombia: Compilación Bibliográfica. Popayan: Universidad del Cauca. Colección politicas de la alteridad.

Restrepo, E. (2005). Políticas de la teoría y dilemas en los estudios de las colombias negras. Cauca: Universidad del Cauca. Colección política de la Alteridad

Restrepo, E. (2003). Entre aracnidas deidades y leones africanos: contribución al debate de un enfoque afroamericanista en Colombia. Bogotá: Tabula Rasa.

Riascos, W. (2001). Raices culturales del pueblo afroamericano y caribeño, en AA. VV., Teología Afroamericana y Hermenéutica Bíblica. Bogotá: ed Kimpres Ltda.

Rodríguez Gómez, G., \& Otros, Y. (1996). Metodología de la investigación cualitativa. Málaga: Ediciones Algibe, S.L.

Touraine, A. (2000). ¿Podremos vivir juntos? Mexico: Fondo de cultura Económica.

Vásquez, M. (1994). Las Caras Lindas de mi Gente Negra. Santafé de Bogotá: Plan Nacional de Rehabilitación PNR. 